\title{
Boston Bowel Preparation Segment Score
} 1

National Cancer Institute

\section{Source}

National Cancer Institute. Boston Bowel Preparation Segment Score 1. NCI Thesaurus.

Code C138208.

Portion of mucosa of the colon segment seen, but other areas of the colon segment not well seen due to staining, residual stool and/or opaque liquid. 